\title{
THE EQUILIBRIUM DISTRIBUTION OF POPULATION AND WAGES IN A SYSTEM OF CITIES
}

\author{
James R. Kahn and Haim Ofek*
}

\begin{abstract}
The positive relationship between wages and city size is shown to be consistent with equilibrium conditions predetermined by the dynamics of market forces. This means that wages are expected to rise with city size under diverse technological and institutional conditions, assuming mobility is unimpaired. A new interpretation for a widely observed statistical regularity is thus suggested. The new interpretation is consistent with conventional economic explanations (driven by the principle of compensating wage differentials in the presence of urban disamenities and rising costs of living). It is less restrictive, however. Sweeping assumptions about deteriorating amenities or rising cost of living throughout the entire range of city size are no longer required. These conditions need only hold in the immediate vicinity of equilibrium. In fact, their existence is shown to be a direct outcome of equilibrium, rather than an independent ex ante cause.
\end{abstract}

\section{INTRODUCTION}

A positive relationship between city size and wages has been observed in a large number of empirical studies (Fuchs 1967; Hoch and Drake 1974; Segal 1976; Rosen 1979; Roback 1982; Clark, Kahn, and Ofek 1988; and Whaples 1991, to name but a few). ${ }^{1}$ There are a number of explanations for this statistical regularity. The explanation most prevalent among economists (e.g., Tolley 1974) relies on compensating wage differentials due to the increasing cost of living (particularly costs of housing and commuting) and the typical urban disamenities (crime, pollution, congestion, etc.). The main problem with this argument, however, is that one can use compensating wage differentials to suggest either a direct or inverse relationship between wages and city size. Unfavorable characteristics of urban life, like those mentioned above, imply a direct relationship. Other characteristics (cultural and recreational amenities, economies of scale in consumption, and lower costs of search in larger urban labor markets) imply an inverse relationship. Insights gained from the principle of compensating wage differentials therefore suggest an open, empirical question rather than a clear, theoretical prediction. As such, they do not mitigate the need for a more general explanation.

\footnotetext{
*Associate Professor of Economics, University of Tennessee and Oak Ridge National Laboratory, and Associate Professor of Economics, State University of New York at Binghamton, respectively. The authors would like to thank Phillip Nelson for his insightful comments. Particular acknowledgement is due to David Clark, who is a coauthor of related papers. Any errors are the responsibility of the authors.
} 
An attempt to explore a more general explanation is made in this paper. We propose to use a model of spatial equilibrium and examine conditions under which it reaches dynamic stability. Dynamic stability conditions dominate observed phenomena, because unstable equilibria represent states that one is unlikely to observe. Inasmuch as dynamic stability is shown to imply rising wages with city size, one obtains a compelling explanation for the problem at hand. The following analysis is driven largely by this idea.

\section{STATIC EQUILIBRIUM}

The model relies on the basic assumption that economic units seek optimal location within and across cities. Equilibrium is achieved when firms and households are left with no incentive to relocate. The standard assumptions of the urban monocentric model are employed, except that cities are not fixed in geographic size but expand up to the point where the rental price of residential land is equal to the rental price of agricultural land (assumed to be a constant throughout the system).

\section{Consumption and Labor Supply}

The household utility function is given by

$$
u=u[x, h, Z(N), A],
$$

where $x$ is a nationally traded (composite) good; $h$ measures living space; $Z$ is a vector of amenities (or disamenities) all related to city size $N$; and $A$ is a vector of amenities specific to the site on which the city is located but unrelated to its size. Typical examples of $Z$ are congestion and pollution, whereas typical examples of $A$ are sunshine and rainfall. ${ }^{2}$ For simplicity, it is assumed that both types of local amenities vary across cities but otherwise are equally applicable to all sites within a city. Utility is maximized subject to a budget constraint,

$$
x+r h=(1-d) w,
$$

where the price of $x$ is normalized on $1, r$ is the rental price of housing, $d$ is the associated distance from the center measured in commuting time and expressed as a fraction of the standard working day $(0<d<1)$, and $w$ is the wage rate for the standard working day.

Optimization can be viewed as a two-stage sequence. First, utility is locally maximized with respect to $x$ and $h$, holding $N$ and $A$ (i.e., location) constant, which determines an indirect utility function conditional on location: 


$$
u=v[r,(1-d) w ; N, A],
$$

where all the arguments $(r, d, w, N$, and $A)$ are understood to vary with location. The second stage thus involves optimal relocation (within and across cities, if needed) to the point where (3) is unconditionally maximized to yield

$$
\max u=U^{*} \text {. }
$$

So defined, $U^{*}$ is the maximum level of utility attainable throughout the system by a geographically mobile household. Assuming homogeneous households, the value of $U^{*}$ is unique at any time and pertinent at any site where households choose to locate. ${ }^{3}$ Utility equalization is achieved through compensating adjustments in two variables: wages $(w)$ and rents $(r)$. Compensating wage differentials equalize $U^{*}$ across cities. Differences in rental prices of housing equalize $U^{*}$ within cities. The entire process is best summarized by a wage acceptance function.

The wage acceptance function is obtained by solving $w$ from (3) and (4), which immediately yields the first equality in the following expression (leaving the second equality to be established shortly).

$$
w_{a}=\frac{e\left(r, U^{*}, N, A\right)}{1-d}=\frac{e\left(R, U^{*}, N, A\right)}{1-D(N)}
$$

Here $w_{a}$ should be interpreted as the minimal wage rate a worker requires to stay in a particular location given its distance from the center $(d)$, cost of housing $(r)$, and the characteristics of the chosen city $(N, A)$. The term on the far right of (5) evaluates the wage acceptance function from the perspective of a household located at the edge of the city. At this point, the distance from the center is equivalent to the radius of the city $(D)$, and the rents equal the agricultural price of land $(R)$. Hence, the rightmost term is obtained by substituting $r=R$, assuming the radius of the city is a function of its population size $d=D(N)$.

The necessary justification for the second equality in (5) above relies on wage equalization across neighborhoods within a city. Assuming a negligible effect of commuting on job performance, profit-maximizing employers will be indifferent to residential choice by employees. In equilibrium, identically productive workers are thus expected to earn equal wages regardless of residential location. The second equality in (5) simply indicates that workers who choose to live at or near the edge of the city are no exception to this rule. ${ }^{4}$

In the aggregation of the wage acceptance function, one needs only to examine residents at the very edge of the city. Specifically, we can concentrate on the rightmost term of (5) and note once again that $U^{*}$ and $R$ are both systemwide 
constants and thus can be dropped. Therefore, the wage acceptance function (5) can be greatly simplified into

$$
w_{a}=H(N, A) \text {. }
$$

Equation (6) may be viewed as an aggregate wage acceptance function. It specifies the minimum wage $\left(w_{a}\right)$ that potential workers require to locate in a particular city, given its amenities $(A)$ and size $(N)$. The particular sites within the city no longer need explication. As such, Equation (6) can also be interpreted as an (inverted) labor supply to a single city. Of special interest here is the slope $\left(d w_{a} / d N\right)$ of this function. In fact, one objective of this paper is to show that this slope can be signed unambiguously at equilibrium. ${ }^{5}$

\section{Production and the Demand for Labor}

A similar optimization problem confronts a firm. The solution depends, however, on the industry in which the firm operates. In a competitive urban market, the situation of a firm, say, in industry $i$, is best stated by the zero-profit, positiverate-of-return condition imposed on its profit function:

$$
\pi^{i}\left(w, r_{0}, p_{i}, I^{*} ; N, B\right)=0, \quad(i=1, \ldots, k)
$$

where the rate of return on capital $I^{*}$ and product price $p_{i}$ are both positive and identically constant over the entire system due to free mobility of capital and goods. Other arguments of the profit function are free to fluctuate across cities. These include wages $(w)$, rents at the center of the city where the firm is presumably located $\left(r_{0}\right)$, city size $(N)$, and a vector of producer amenities specific to the site on which the city is located $(B)$. The superscript $i$ (over $\pi$ ) indicates that the functional form is specific to the industry. If $k$ competitive industries $(i=1, \ldots, k)$ operate in the city, then there are $k$ distinct types of such profit functions, each of which must satisfy the condition stated in Equation (7).

The rental price of land at the business district (i.e., at the center) can be expressed as a rising function in wages and city size:

$$
r_{0}=r(w, N), \quad r_{w}, r_{N} \geq 0 .
$$

Now, solving (7) and (8) for $w$, and noting that both $p_{i}$ and $I^{*}$ drop out as constants, one obtains the producer's break-even wage function

$$
w_{b}=\stackrel{i}{f}\left(r_{0}, N, B\right), \quad(i=1, \ldots, k),
$$

namely, the maximum wage a producer can pay short of suffering losses. The profit function (7) and the break-even wage function (9) are the firm's analogy of the household's indirect utility function and wage acceptance function, (3) and 
(5), respectively. The analogy is not perfect, however. The dissimilarities are apparent in the aggregation.

The main problem of aggregation is that the profit function (7) is industry specific, as is the breakeven function (9). Both have functional forms that vary (across industries) as arbitrarily as technology of production varies across different products. The problem cannot be resolved by lumping together all industries into a single industry (i.e., assuming uniform production conditions), because this will rule out the main reason for market exchange among cities. The problem can be treated more adequately by recognizing that many industries may operate in a city, and that one reason for trade is variation in the industrial mix across cities.

To construct a multi-industry break-even wage function, we maximize (9) over industries $(i=1, \ldots, k)$ to obtain the maximum value envelop:

$$
w_{b}=\underset{\max i}{f^{i}}(N, B)=F(N, B), \quad(i=1, \ldots, k) .
$$

So defined, the aggregate break-even wage function implicitly involves a selection process to determine the local industrial mix. Only those industries are selected (i.e., choose to operate in a city) that can offer the highest local wage without loss. This mix will include one or more exporting industries in addition to commonplace industries that provide local goods and services (represented in our analysis by the local housing industry). The selection process depends on local conditions: city size $(N)$ and, producers' amenities $(B)$, as well as agglomeration and economies to scale internal to a local industry. Consequently, the break-even function is expected to differ from one city to the next, depending on the local industrial mix.

\section{Existence of Equilibrium}

Taken together, the wage acceptance function $H(N, A)$ and the wage breakeven function $F(N, B)$ suggest an equilibrium condition for a single city: $H(N, A)=F(N, B)$, or in short, $w_{a}=w_{b}$. If the going wage in a city somehow satisfies this condition, then both firms and households are left with no incentive to relocate. In principle, a state of equilibrium is attainable wherever a solution to the equation just outlined exists. Such a state of equilibrium may be vulnerable, however, to prevailing shocks. Changes in technology, demography, or tastes are all bound to generate wages unequal to either $w_{a}$ or $w_{b}$ in the short run. The existence of equilibrium is therefore observationally meaningful only in conjunction with appropriate conditions of dynamic stability. 


\section{DYNAMIC EQUILIBRIUM}

As indicated, the concept of equilibrium is closely associated with the question of stability. Given a system initially at rest in a state of equilibrium, say $N^{*}$, one can ask the following question. If some isolated shock somehow disturbs the system, will it steadily return to $\mathrm{N}^{*}$, or will it wander away? Depending on the answer to this question, the system is said to be stable or unstable, respectively. The specific purpose of this section is to identify conditions of stability under which dynamic equilibria of cities are attainable.

Equilibrium in a competitive market is characterized by equalization of all offer and bid prices. There is no guarantee that this condition will always take effect, especially in short-term market situations. The local labor market is no exception. Local demand shocks may readily establish a market wage $(w)$ unequal to either the acceptance wage $\left(w_{a}\right)$ or the breakeven wage $\left(w_{b}\right)$. However, this situation is less likely to persist in the long run. If the going wage initially exceeds the wage acceptable to workers $\left(w>w_{a}\right)$, then more workers will move into the city, driving down marginal productivity of labor and wages until the gap is closed. By similar logic, a going wage that falls short of the break-even wage $\left(w<w_{b}\right)$ would lead to an inflow of capital (by producers who seek to capture the associated rents) and, in the process, drive up marginal productivity of labor and wages, again, until the gap is closed. Obviously, if these gaps are reversed, then labor and capital will flow in opposite directions. In general, the time path of labor $N$ and capital $K$ can be approximated as functions of such wage gaps: ( $w$ $\left.w_{a}\right)$ and $\left(w_{b}-w\right)$, respectively. That is,

$$
\begin{array}{ll}
\dot{N}=\beta\left(w-w_{a}\right), & \beta>0, \\
\dot{K}=\alpha\left(w_{b}-w\right), & \alpha>0,
\end{array}
$$

where dots above symbols represent derivatives with respect to time, i.e., $\dot{N}=N^{\prime}(t), \dot{K}=K^{\prime}(t)$, etc. By drawing on a simple principle of the marginal productivity theory of wages, one can treat wages as a rising function of capital and as a falling function of labor. Hence, the time path of wages can be traced to the time paths of labor and capital by the following equation:

$$
\dot{w}=\gamma \dot{K}-\delta \dot{N}, \quad \gamma, \delta>0 .
$$

Equations (11), (12), and (13) represent a self-contained system that is consistent with the implications discussed above. Equation (11) implies net immigration to a city whenever the going local wage rises above the acceptance wage. The resulting increase in the local labor force will then have a depressing effect on wages as evident in the second term of (13). Equation (12) implies that profits generated whenever the market wage falls short of the break-even wage will in- 
duce capital inflow. The resulting positive effect on wages is then evident in the first term of Equation (13). Of course, wage disparities in the other direction will have corresponding opposite effects.

The main implications of the three-equation system just outlined can be usefully summarized in a single equation. Indeed, substituting from (11) and (12) into (13) yields

$$
\dot{w}=\alpha \gamma\left(w_{b}-w\right)-\beta \delta\left(w-w_{a}\right) .
$$

It should be noted that while the four adjustment coefficients $(\alpha, \beta, \gamma, \delta)$ are positively signed, no restrictions (either relative or absolute) have been placed on their magnitudes.

With Equation (14) at our disposal, we are now prepared to apply a fairly accessible phase-diagram analysis to the problem at hand. ${ }^{6}$ Figure 1 illustrates the six possible configurations (Panels 1-A to 1-F) the wage acceptance and breakeven functions can jointly take at equilibrium. The directional arrows represent the dynamic forces implied by Equations (11) and (14). The horizontal solid arrow is associated with (11), the vertical open arrow is associated with the first term of (14), and the vertical solid arrow is associated with the second term of (14). Consider, for instance, the area immediately to the left of equilibrium in Panel 1-A. In this section of the diagram, we find that $w>w_{a}$, hence a positive effect on migration and (consequently) a negative effect on wages are expected. These theoretical expectations are depicted by the two solid arrows pointing down and to the right. On the other hand, we have $w<w b$, hence net inflow of capital and (consequently) a positive effect on wages are expected, as suggested by the corresponding upward-pointing open arrow. The same logic is applicable to other parts of Figure 1.

The resulting directional arrows determine well-defined regions of attraction (the light areas) and regions of repulsion (shaded areas) about equilibrium for each configuration in Figure 1. Only two configurations (1-A and 1-B in the diagram) produce "basins of attraction" that are uninterrupted by regions of repulsion. Hence, these two are the only (unconditionally) stable configurations. The distinguishing feature shared by these two configurations includes the following conditions on the slopes of the acceptance and the break-even functions, denoted $\mathrm{s}$ and $\mathrm{v}$, respectively:

1. $s>0$ (i.e., the slope of the acceptance function is positive); and

2. $s>V$ (the slope of the acceptance function is larger than the slope of the break-even function).

Both conditions must take effect, or there is no guarantee of dynamic stability. Indeed, it is readily apparent from an examination of the remaining four diagrams that violation of either condition ( $s>0$ or $s>v$ ), or both, will generate dynamical- 


\section{FIGURE 1}

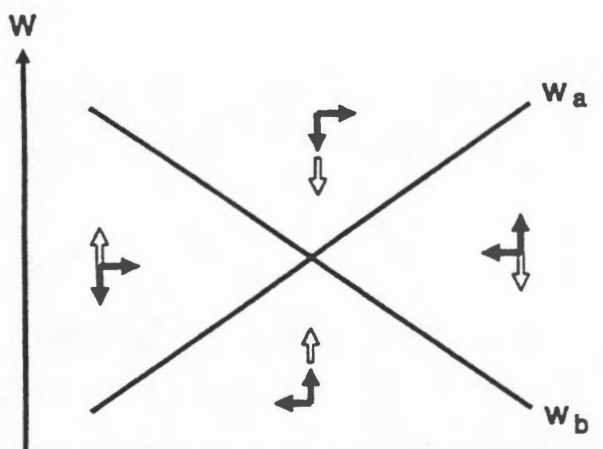

Panel 1-A: $(s, 0, v)$

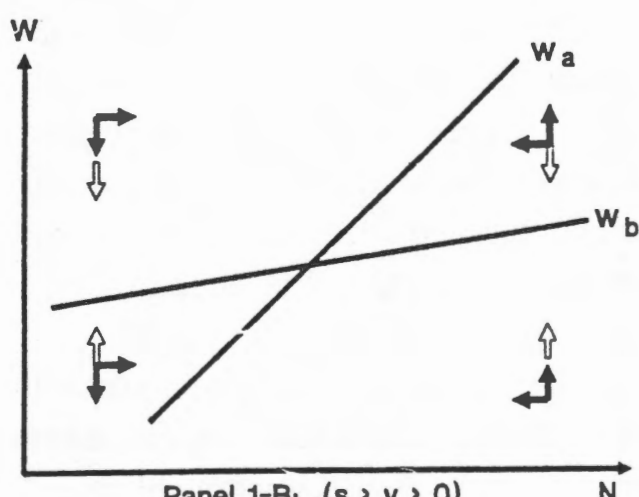

Panel 1-B: $(s, v, 0)$

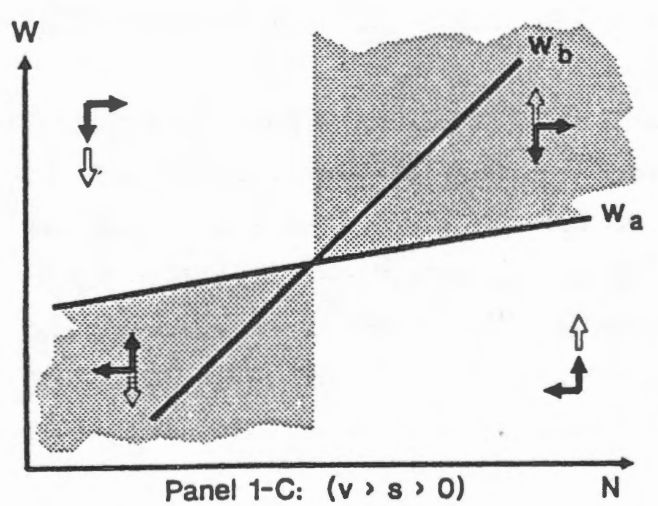

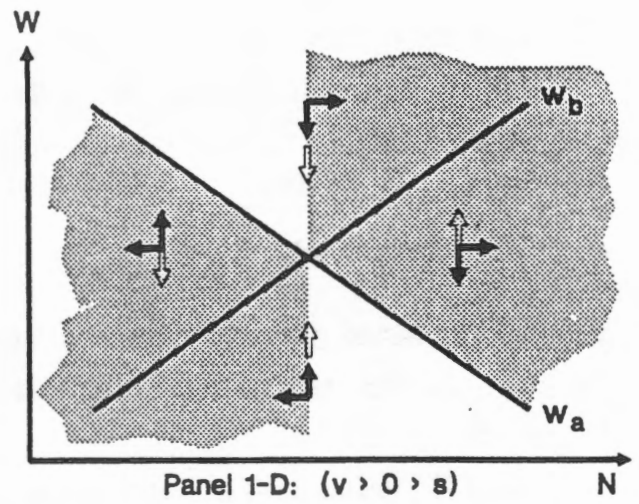
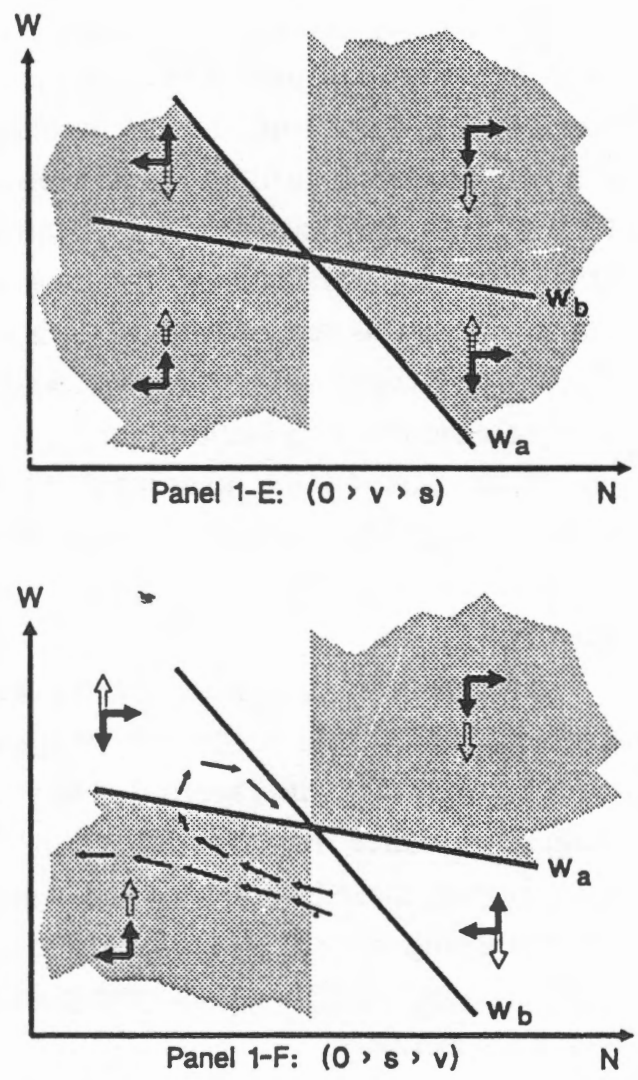
ly unstable situations. None of these four configurations (1-C to 1-F in Figure 1) jointly satisfies the two stated conditions, and consequently none is (unconditionally) stable. To be exact, the three configurations (1-C, 1-D, and 1-E) that violate the condition $\mathbf{s}>\mathrm{v}$ are all inescapably unstable. The final configuration that satisfies $s>v$ but violates $s>0$ is unstable in general, though it can be seen (upon inspection of Panel 1-F) that it may become stable under special conditions. Stability in this particular instance cannot be ruled out, yet the overriding consideration is that it cannot be guaranteed, either. The mere existence of such an uncertain possibility, which puts configuration 1-F at limbo, is of some interest to the ensuing discussion.

In sum, the phase diagram analysis suggests that a stable equilibrium can be assured only when the wage acceptance function is positively sloped and (positively) steeper than the break-even function. This conjecture can be given an intuitive explanation. Assuming a positively sloped wage acceptance function, the growth of a city will make it a less pleasant place to live, thereby inhibiting further expansion. Such a self-correcting mechanism does not exist for a downwardsloping wage acceptance function under identical circumstances. If this is the case, then an increase in city size will make it a nicer place to live, attracting more people and hence accelerating rather than inhibiting its growth.

The conjecture just outlined has important implications for the problem at hand. Cities along the upward sloping portion of the wage acceptance function will be observed frequently. Cities along the downward sloping portion of this function will be observed infrequently, if at all. This implies, on balance, a direct relation between city size and wages.

\section{EMPIRICAL IMPLICATIONS}

In most practical situations, it is impossible to observe wage acceptance and break-even functions, given data on a single city (because of insufficient variation in $N$ ). One is forced to rely on multi-city data. Problems of aggregation and identification are therefore inescapable. It would be appropriate to linger for a while on these problems before we discuss actual observations.

\section{The Question of Identification}

When the relationship between wages and city size is observed in a multicity cross section, there is no guarantee it will identify either the acceptance or the break-even equation. Strictly speaking, what one observes is a locus of equilibria between these two structural equations. Obviously, such a locus of equilibria is 
empirically meaningful only when it falls along or sufficiently close to (i.e., when it identifies) one of these structural equations. Which of the two equations, if any, is actually identified is a question largely dependent on variability in the data. A salient rule of thumb suggests that a locus of equilibria is likely to identify that particular structural equation that exhibits the least variability across observations. Following this line of reasoning, we shall argue that the observed relation between wages and city size is likely to identify the acceptance function.

To ascertain this argument, we have no need to assume homogeneity of consumers across cities. A certain degree of heterogeneity in consumption (thus variability in the acceptance function) is admissible, as long as it falls short of the degree of heterogeneity in production (variability in the breakeven function). In other words, the entire argument is based on the assumption that the volatility in $F(N, B)$ across cities exceeds the volatility in $H(N, A)$. Three different reasons in support of this assumption are outlined below.

One reason why heterogeneity in production across cities is unmatched by heterogeneity in consumption is associated with the industrial diversity across cities. This reason is valid, even if the degree of heterogeneity among individual producers and among individual consumers is the same. Indeed, from a purely technological point of view, consumption is arguably equivalent to "home production": a nonmarket industry that specializes in the production of utility and uses market goods and services as inputs. To follow this argument, suppose the technology in home production and in market production within an industry are usually equally heterogeneous across cities. Moreover, suppose consumers' and producers' amenities are likewise equally heterogenous. If this is the case, then there is no reason why the variation across cities in the acceptance function $H(N, A)$ will differ from the variation in the break-even function, $f_{i}(N, B)$ for any given industry $(i=1, \ldots, k)$. However, what matters is the variation in the aggregate city break-even function $F(N, B)$, rather than in industry-specific ones. But the degree of variation in $F(N, B)$ exceeds the degree of variation in $f_{i}(N, B)$ by a factor equal to the degree of heterogeneity in technology across industries (as evident from the discussion above). Hence, as long as cities differ in their industrial mix, which they certainly do, one can expect $F(N, B)$ to be more volatile than $H(N, A)^{8}$

Differences in volatility may result from other sources. However, of all conceivable sources of heterogeneity, differences in technology across industries are probably the best defined and the least speculative. We consider it to be an overriding, though not exclusive, factor leading to the identification of the wage acceptance function.

An additional factor is aggregation. Recall again that in dealing with the problem of identification in a cross section of cities, all variations refer to city ag- 
gregates. Variations among individual producers and consumers, or among subgroups of such individuals within a city, are not at issue. Aggregation in its very nature tends to eliminate or reduce any source of unsystematic variation in the data. When one considers the major factors in the formation of consumption patterns (age, gender, family size, education, income, etc.), there seems to be relatively little systematic variation across city aggregates. Indeed, there is considerably less variation in the characteristics of the average household across different cities than, say, in those of the average household across neighborhoods within a city-to say nothing about variations across individual households. ${ }^{9}$ In contrast, differences in the industrial mix are a systematic source of variation across cities. Variation in production ascribed to this factor is not eliminated by aggregation. Aggregation thus reduces the volatility in consumption but leaves much of the volatility in production intact.

Working knowledge of data and methods of estimation should remove further doubts concerning the identification of the wage acceptance function. Wage data are typically obtained from households and are accompanied by fairly detailed information about personal and household characteristics such as those listed above. Studies based on microdata often use this supplementary information in order to adjust wages for these characteristics. In the process, variability among households is reduced. Estimations in some studies are further adjusted for local amenities (sunshine, rainfall, temperature, availability of outdoor recreation sites, etc.), which are, for the most part, consumer amenities. Again, the variability affecting the acceptance function is reduced with no impact on the break-even function. The likelihood of identifying the wage acceptance function is thus further enhanced.

\section{The Observed Relationship between City Size and Wages}

Table 1 shows the rate of change in wages with respect to city size as estimated by various authors. The findings are extremely suggestive of an overall positively sloped wage acceptance function, although not all the authors have interpreted their own results as wage acceptance functions. A major study by Nordhaus and Tobin (1973) examined the relationship between wages and population but was excluded from the summary in this table because it studied population by county rather than by city or metropolitan area; therefore, it is not really comparable to the other studies. It should be noted, however, that Nordhaus and Tobin found a positive relationship between wages and population on a county basis. To our knowledge, the only study that has found a negative (though statistically insignificant) relationship between wages and city size is that of 
TABLE 1

Studies That Have Examined the Relationship between Wages and City Size

\begin{tabular}{|c|c|c|c|c|c|}
\hline Study & $\begin{array}{c}\text { Dependent } \\
\text { Variable }\end{array}$ & $\begin{array}{l}\text { Independent } \\
\text { Variable }\end{array}$ & Coefficients & $\begin{array}{c}\text { Maximum } \\
\text { Point }^{2}\end{array}$ & Sirnificance \\
\hline Fuchs (1967) & Real wages & Size dummies & Rising with size & N.A. & $>95 \%$ \\
\hline Hoch (1972) & Real wages & $\ln$ (city size) & .13 to .22 & N.A. & $>95 \%$ \\
\hline \multicolumn{6}{|l|}{ Hoch and } \\
\hline Drake (1974) & Real wages & In (city size) & 6.10 & N.A. & $>95 \%$ \\
\hline Segal (1976) & Real income & Size dummies & rising with size & N.A. & $>95 \%$ \\
\hline Meyer and & $\ln$ (real wages) & ln (city size) & & & \\
\hline \multirow[t]{3}{*}{ Leone (1977) } & Skilled workers & & -.01 & N.A. & $>68 \%$ \\
\hline & Unskilled workers & & -.003 & N.A. & $>53 \%$ \\
\hline & Computer analysts & & -.01 & N.A. & $>59 \%$ \\
\hline \multirow[t]{2}{*}{ Rosen (1979) } & Real wages & City size & $1.04 \mathrm{e}-7$ & N.A. & $>95 \%$ \\
\hline & Nominal wages & City size & $0.966 \mathrm{e}-8$ & N.A. & $>95 \%$ \\
\hline Hoch (1982) & real wages & $\ln$ (city size) & 8.36 to 11.36 & N.A. & $>95 \%$ \\
\hline Roback (1982) & ln (weekly wages) & City size & $.16 \mathrm{e}-7$ & N.A. & $>95 \%$ \\
\hline $\begin{array}{l}\text { Clark and } \\
\text { Kahn (1988) }\end{array}$ & ln (real wages) & $\ln$ (city size) & .026 & N.A. & $>95 \%$ \\
\hline Clark, Kahn \& & ln (hourly wages) & City size & .0087 & N.A. & $>95 \%$ \\
\hline \multirow[t]{2}{*}{ Ofek (1988) } & & $c s, c s^{2}$ & $.068,-.007$ & 4.86 & $>95 \%$ \\
\hline & & $c s, c s^{2}, c s^{3}$ & $.1,-.018,00085$ & 3.74 & $>95 \%$ \\
\hline \multirow[t]{2}{*}{ Whaples (1991) } & ln (weekly wages) & City size, cs $^{2}$ & $.04999,-.00355$ & 7.04 & $>95 \%$ \\
\hline & & & $.04930,-.00435$ & 5.67 & $>90 \%$ \\
\hline \multirow{2}{*}{$\begin{array}{c}\text { Ofek, Kahn, \& } \\
\text { Clark (1991) }\end{array}$} & In (hourly wages) & City size & .018 & N.A. & $>95 \%$ \\
\hline & & City size, $\mathrm{cs}^{2}$ & $.064,-.008$ & 4.00 & $>95 \%$ \\
\hline Ofek and & In (hourly wages) & City size & & & \\
\hline \multirow[t]{4}{*}{ Merrill (1992) } & Married women & & .0217 & N.A. & $>95 \%$ \\
\hline & Married men & & .0106 & N.A. & $>95 \%$ \\
\hline & Single women & & .0171 & N.A. & $>95 \%$ \\
\hline & Single men & & .0165 & N.A. & $>95 \%$ \\
\hline
\end{tabular}

'Estimated city size (population in millions) associated with maximum wages.

Meyers and Leone (1977). All other studies report a positive and statistically significant slope of wages with respect to city size.

From the point of view of the present paper, we consider it important to examine the relationship between wages and city size over their entire range as well as the behavior of this relationship in narrower segments. The question is whether the positive slope holds true for large cities as well as for medium and small ones. This question calls for a nonlinear specification. The usual procedure is to fit a polynomial specification to data and then to find out whether any extremum point occurs within the relevant range of city size. Three of the studies cited in Table 1 report such a procedure. All three have obtained maximum points within the relevant range of the data, implying an inverted U-shaped wage acceptance func- 
tion. The critical points range from 3.7 to 7 million in population size. The largest cities (New York, Los Angeles, Chicago, and possibly Philadelphia) thus seem to fall along the downward sloping right-hand side tail of the wage acceptance function. $^{10}$

In general, however, the population is distributed according to the prediction that the relationship between city size and wages is positive. Although the four cities mentioned above are the largest in the system, they do not account as a group for more than 15 percent of the total population of the United States. Moreover, we should note the relatively large gaps in size among Philadelphia (with a population of 4.8 million), Chicago ( 7 million), Los Angeles ( 7.5 million), and New York (9.1 million). The gap between Chicago and Philadelphia, for example, is large relative to both the distribution as a whole and the smaller gaps within the distribution of cities whose populations are less than that of Philadelphia. ${ }^{11}$

The fact that large gaps (or low density) in the distribution coincide with a negatively sloped range of the wage acceptance function should come as no surprise. Recall (from the dynamic analysis in Section III) that a stable equilibrium in this range is deemed improbable, but not impossible. In other words, if there is a negatively sloped range of the wage acceptance function (a violation of the condition $s>0$ ), then few if any cities will exist there, because they will tend to be dynamically unstable. Dynamic instability seems thus to generate these large gaps in the distribution of city size.

\section{CONCLUSION}

In summary, there appears to be considerable evidence that the overall observed relationship between city size and wages is positive. The predominance of population is located along portions of the function where wages rise with city size. Those cases where wages fall with city size involve large cities as well as large gaps in the distribution. These observations are fairly consistent with the conditions predicted by the analysis of dynamic stability. In fact, the overall agreement between theory and observation on this particular phenomenon underscores the usefulness of the analysis of dynamic stability in providing explanations for observed phenomena. 


\section{ENDNOTES}

1. For a summary of the main results of these and other studies, see Table 1 and the discussion in Section IV.

2. See Clark, Kahn, and Ofek (1988) for a complete discussion of these concepts.

3. Though $U^{*}$ is fixed to the individual, it may vary in response to changing conditions at the level of the system. It should be noted that under rational expectations, the long-term level of $U^{*}$ will remain relevant to observed behavior even when it is temporarily unattainable. The analysis may thus accommodate situations in which the system is temporarily out of equilibrium or situations in which short-term barriers to intercity mobility are present.

4. By the same logic, wage differentials cannot compensate for the cost of commuting or for any other aspect of residential choice within a city, because such differentials will tend to vanish in equilibrium. Under these conditions, equalization of utility across different sites within a city must be maintained by trade-offs between the rental price of housing $(r)$ and the distance to the center (d). Conversely, there is no reason for wage differentials among cities to vanish. In fact, the existence of intercity wage differentials is the only guarantee for the equalization of utility across cities in equilibrium.

5. To this point, however, very little can be said about the slope of the wage acceptance function. Writing (6) explicitly as $w_{a}=E(N, A) /(1-D(N))$, consider the partial derivative with respect to $\mathrm{N}$

$$
\frac{\partial w_{a}}{\partial N}=\frac{E_{N}+w D^{\prime}}{1-D} \text {. }
$$

It is clear that the two terms $w D^{\prime}$ and $1-\mathrm{D}$ on the right-hand side are both positive. They represent the marginal cost of commuting to the edge of the city and the corresponding discounting factor associated with this type of commutation, respectively. Unfortunately, so far nothing can be said concerning either the sign or the relative size of the third term, $\mathrm{E}_{\mathrm{N}}$ : the rate at which quality of life rises (or falls) with city size. This leaves the slope $\partial w_{a} \partial N$ with a theoretically indeterminate sign.

6. A more rigorous treatment is provided within a mathematical appendix that is available upon request from the authors.

7. These conditions are derived explicitly in the mathematical appendix that is available from the authors.

8. For the degree of heterogeneity in the industrial mix across cities, see Simon (1988). 
9. The heterogeneity in the characteristics of individuals and households across neighborhoods is well demonstrated, for instance, in a recent paper by Duncan, Kato, and Sealand (1991).

10. For the exact positions of these four cities in the distribution of wages over city size, see Figure 1 in Clark, Kahn, and Ofek $(1988,710)$.

11. To measure these gaps, one can use either a linear scale or a logarithmic scale. In both cases, the gap between Philadelphia and Chicago is large relative to the distribution as a whole ( 24 percent and 9 percent of the total distribution, respectively) and significantly larger than the gaps to the left of Philadelphia.

\section{REFERENCES}

Clark, D. E., and J. R. Kahn. "Two Stage Hedonic Wage Approach: A Methodology for the Valuation of Environmental Amenities." Journal of Environmental Economics and Management 16 (1988): 106-120.

Clark, D. E., J. R. Kahn, and H. Ofek. "City Size, Quality of Life and the Urbanization Deflator of the GNP." Southern Economic Journal 54 (1988): 701-714.

Duncan, G. J., P. Kato, and N. Sealand. "Do Neighborhoods Influence Child and Adolescent Behavior?" Unpublished paper, the University of Michigan, July 1991.

Fuchs, V. R. "Differentials in Hourly Earnings by Region and City Size, 1959." National Bureau of Economic Research, Occasional Paper, no. 101, 1967.

Hoch, I. "Income and City Size." Urban Studies 9 (1972): 299-328.

"Climate, Energy Use, and Wages." In The Economics of Managing Chlorofluorocarbons, edited by J. Cumberland, J. Hibbs, and I. Hoch, 269-319. Baltimore: The Johns Hopkins University Press, 1982.

Hoch, I., and J. Drake. "Wages, Climate, and the Quality of Life." Journal of Environmental Economics and Management 9 (1974): 268-295.

Meyers, J. R., and R. A. Leone. "The Urban Disamenity Revisited." In Public Economics and the Quality of Life, edited by L. Wingo and A. Evans. Baltimore: The Johns Hopkins University Press, 1977.

Nordhaus, W. D., and J. Tobin. "Is Growth Obsolete?" In The Measurement of Economic and Social Performance, edited by M. Moss. New York: National Bureau of Economic Research, 1973.

Ofek, H., J. R. Kahn, and D. E. Clark. "The Urbanization Deflator of the GNP, 1919-1984: Reply." Southern Economic Journal 57, no. 4 (April 1991): 1179-1182. 
Ofek, H., and Y. Merrill. "Labor Immobility and the Formation of Male-Female Wage Gaps in Local Markets." Journal of Labor Economics (forthcoming). Roback, J. "Wages, Rents and the Quality of Life." Journal of Political Economy 90 (1982): 1257-1278.

Rosen, S. "Wage Based Indexes of Urban Quality of Life." In Current Issues in Urban Economics, edited by P. Mieskowski and M. Strazheim. Baltimore: The Johns Hopkins University Press, 1979.

Segal, D. "Are There Returns to Scale in City Size." Review of Economics and Statistics 58 (1976): 339-350.

Simon, C. J. "Frictional Unemployment and the Role of Industrial Diversity." Quarterly Journal of Economics (November 1988).

Tolley, G. S. "The Welfare Economics of City Bigness." Journal of Urban Economics 1 (July 1974): 324-345.

Whaples, R. "The Urbanization Deflator of the GNP, 1919-1984: Comment." Southern Economic Journal 57, no. 4 (April 1991). 